\title{
Chapter 24 \\ Incorporating Experiential \\ and Collaborative Learning \\ into Instructional Design of Solar Energy \\ Related Course-A Social Experiential Approach
}

\section{Manoj Kumar Soni $(\mathbb{D})$ and Tamali Bhattacharya}

\begin{abstract}
The conventional teaching method is mostly as a one-way communication be-tween instructor and students, where students go through rote learning and then appear for written exam. Based on their performance in written exam they are graded and judged. This type of system inculcates exam oriented learning approach than to actual knowledge gain. This is a major issue in the present era where students are fed up with exam oriented approach. So there is immense need to bring innovation in teaching methods. Also, along with education, among the students, there is need of growing social awareness specially towards weaker section of society. In order to impart effective learning experiential and collaborative learning has been incorporated in solar energy related courses by the authors at BITS Pilani. During these courses, the students fabricated do-it-yourself type solar cookers and tested the performance of these cookers in normal conditions. In order to have feel of the usage of the fabricated cookers the students were asked to cook some food items using those cookers. After successful completion of these activities, with the help of a NGO students helped the authors to conduct cheap solar cooker workshop for village women at a village near the institute. During the workshop the students helped the village women to fabricate cheap solar cookers. All the activities fabrication, testing and involvement in the workshop was the part of evaluative components for the courses. It was overall a very successful experiential and collaborative learning experiment with social angle involved in it.
\end{abstract}

Keywords Collaborative learning $\cdot$ Experiential learning $\cdot$ Societal awareness

M. K. Soni $(\varangle) \cdot$ T. Bhattacharya

Birla Institute of Technology and Science, Pilani Campus, Pilani 333031, RJ, India

e-mail:mssoni@pilani.bits-pilani.ac.in 


\subsection{Introduction}

In 21st century, skill development is necessary for the Engineering graduates. The total development of skills is very important-creative skills, cooperative skills, management skills, communication skills, leadership skills, teamwork, which develop the positive behavior and attitude to the learner. It is an important mission for the teachers to improve their students' skills in real-life situations and working for the society. Outcome-based education keeps learner at the center of the education system and teacher acts as a facilitator to help them in their learning. Learning by doing has been a principle of thousands of years (Reese 2011). The learning-by-doing principle has been supported widely and in many forms-mainly learn-by-doing, trial-anderror learning, practical experience versus book learning, the practice-theory-practice dialectic and "proof upon practice."

Dale's Cone of Experience is a model that combines several theories related to instructional design and learning processes. During the 1960s, Dale theorized that learners retain more information by what they "do" as opposed to what is "heard", "read" or "observed" (Davis and Summers 2015). At present, this "learning by doing" has become known as "experiential learning" or "action learning" (http://www.queensu.ca/teachingandlearning/modules/active/documents/ Dales_Cone_of_Experience_summary.pdf).

According to Dale's research, the least effective method at the top, which encompasses learning from information presented through reading, hearing, view images, watching videos. The most active method is at the bottom, which involves direct, purposeful learning experiences, such as hands-on or field experience. Direct purposeful experiences represent reality or the closet things to real, everyday life. "Action-learning" techniques result in up to $90 \%$ retention. Here we will examine student projects in two elective subjects "Renewable Energy" and "Solar Thermal Process Engineering" course at Birla Institute of Technology and Science (BITS) Pilani, at Pilani campus in which students' evaluation was done by mid semester and end semester results, project evaluation and from the surveys. The author surveys students project evaluation and measure student achievement of learning outcomes.

The author introduces cooperative and collaborative learning as a teaching learning strategy which means the students grouped together to inspect a particular assignment or topic to maximize their own and each other's learning. Collaborative is an informal method of teaching and learning, based on the idea that learning is a natural social act in which the participants talk, share, plan together to fulfil the learning goal. Collaborative principles are based on the theories of Dewey (2009), Vygotsky (1980), and Bloom (1956). Their collective work focusing on how students learn has led educators to develop more student-focused learning environments that put students at the center of instruction. The learner is the primary focus in collaborative activities, i.e. working in groups, where the main objective is learning by doing. The structured approaches to developing solutions to the real world problems incorporated in the learning (Theodore 1999; Dewey 2009; Vygotsky 1980; Bloom 1956). 
The authors focus to project based learning, which is a form of active learning, based on inter disciplinary means combination of two to more academic disciplines into an activity. This type of pedagogy mainly applies to learner' life and teacher considers to learner' need and interests. Learners need to be educated in such a way that they work for their community and be responsible for community affairs.

Experiential learning helps in learning course quickly as it is learning while doing. This was tried in solar energy related course. In this total of about 40 students were involved. The basic concepts about solar energy and solar cookers are discussed in the class.

\subsection{Fabrication of Solar Cooker}

The students were divided into small teams comprising of minimum two to maximum four students. The team formation was left to the students as per their choice. They informed the instructor once their teams are formed. The do-it-yourself designs of various solar cookers are shared with the students. They gone through various design and selected suitable design for fabrication. Students were asked to first fabricate a small size model using paper or cardboard to understand intricacies involved in the actual fabrication purpose. For fabrication of prototype the corrugated plastic sheets, anodized aluminum reflector sheets and required tools were made available to the students in the institute workshop. The students went to workshop as during working hours as per their free time between classes and fabricated various solar cookers using corrugated plastic sheets for strength and then mounted anodized aluminum sheets on the sheets. Figure 24.1 represents the pictures of the fabrication of solar cookers by the students. During fabrication, students have to manage their schedule in such a fashion that they are attending classes as well as during office hours and their free time they had to manage the entire fabrication process.

\subsection{Testing of Solar Cookers}

After fabrication, the solar cookers were tested by students. For the same water, cooking pot, thermocouples and data logger were made available to the students. The students used transparent polythene bag for creating greenhouse effect. The radiation data was recorded using Pyranometer. The students recorded data for certain time period and then evaluated the performance of each solar cooker using recorded data. The testing of solar cookers is represented by pictures in Fig. 24.2. 

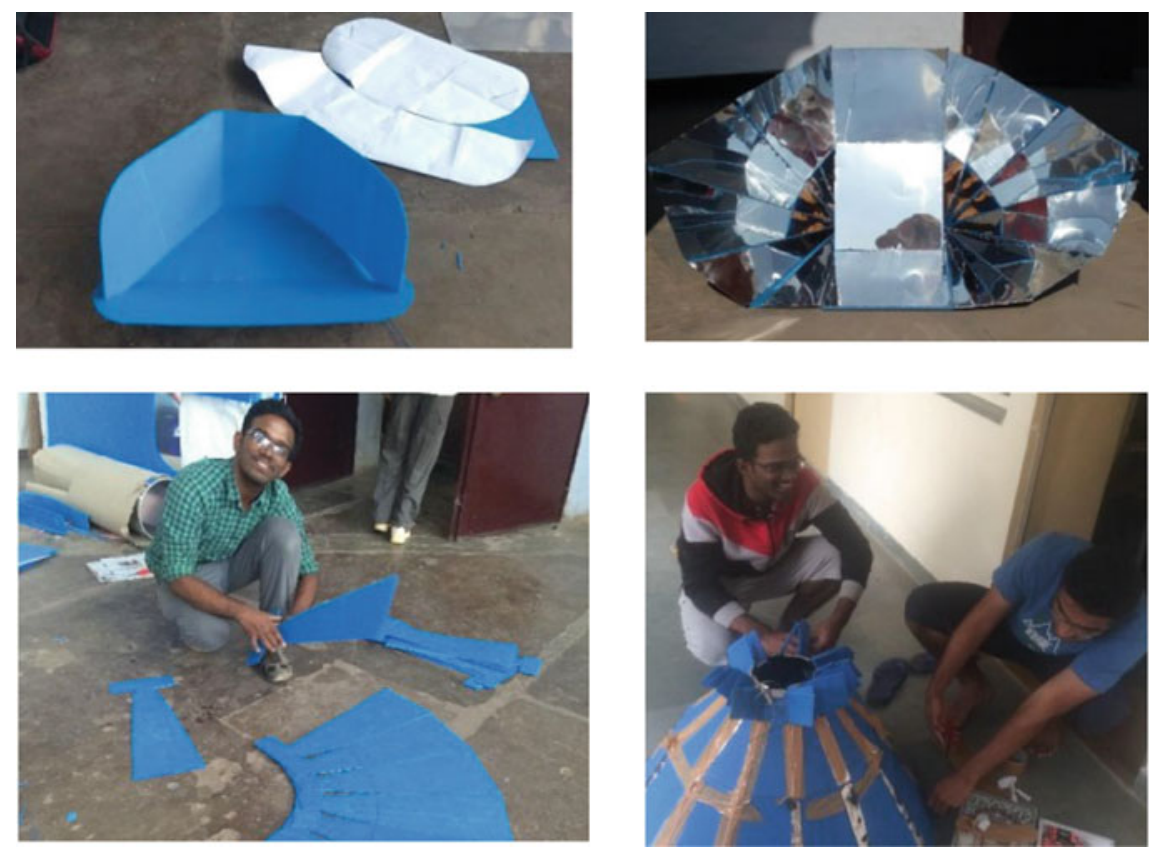

Fig. 24.1 Fabrication of solar cookers by the students
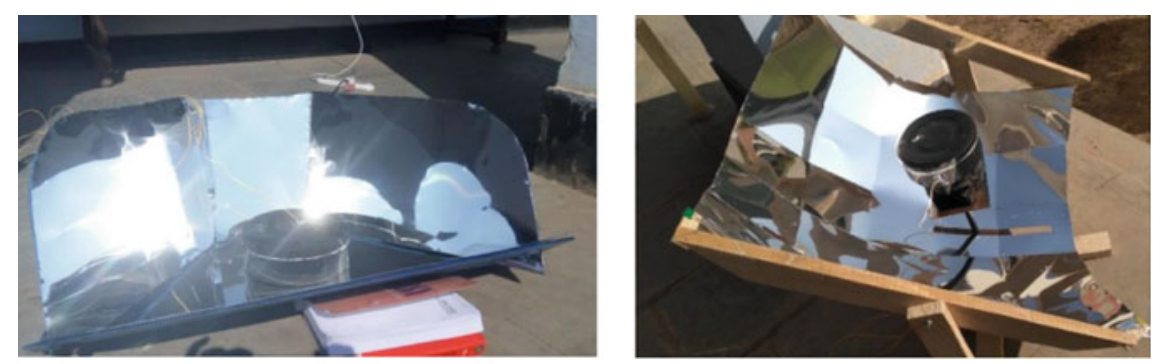

Fig. 24.2 Testing of solar cookers

\subsection{Cooking Using Solar Cookers}

Whenever a product is made it is important to understand its usability and related aspects from consumer's point of view. Keeping this in mind, the students were asked to now use the solar cooker they fabricated by cooking some simple food like noodles, rice, etc. as they are not expert in cooking. They were very excited and cooked noodles and rice using solar cookers they fabricated. The students also noted down the time required to cook the food. Students were asked to cook with polythene 

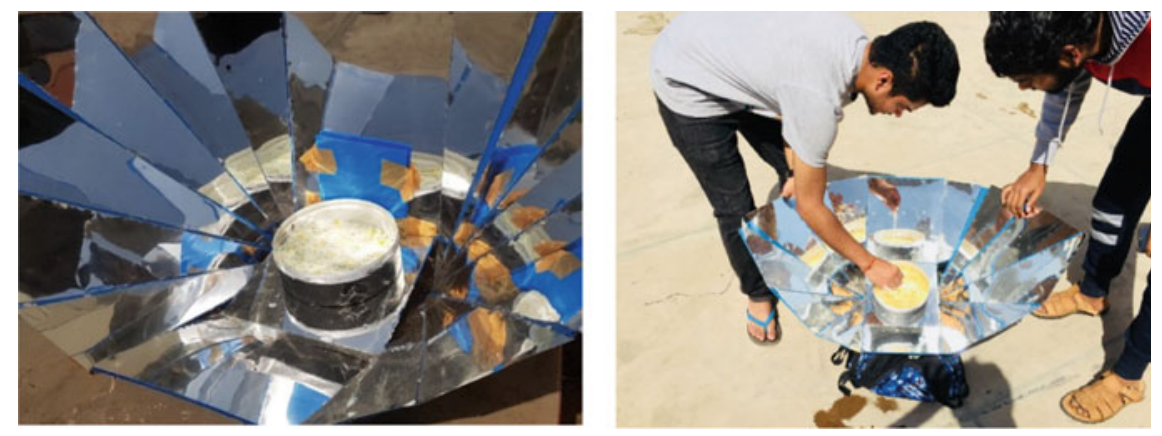

Fig. 24.3 Cooking using solar cookers

cover and without cover both in order to understand the importance of minimizing losses (Fig. 24.3).

\subsection{Workshop for Village Women}

Apart from involved in quality research and imparting technical education, educational institutes should inculcate social responsibility among the student. BITS Pilani is located in a small town Pilani in Rajasthan. It is surrounded by many small villages. In villages, cooking is mainly done on chullah by burning wood. This type of coking has harmful impact on the health of women due to the exposure to fumes and exhaust gases. In order to instill social responsibility in the students and help the village women to reduce cooking with chullah and associate problems, a workshop on fabrication of cheap solar cookers (@1\$) was conducted for them with the help of students registered in the course and Nirmaan Organization. Nirmaan is a NGO that was started by BITS Pilani students in 2005. It mainly works in the areas of education, livelihoods and social leadership. The workshop was conducted on 1st April, 2018 at Khedla ka Baas village which is three kilometers from the campus. About 33 village women and 15 kids were present in the workshop.

For fabrication of solar cookers cardboard boxes and cheap Reflective Mylar sheet were used. The workshop was conducted with an aim to educate village women about usage of solar energy using solar cooker and show its effectiveness and give the women an alternative to fuel wood for cooking. All the students registered in the course participated enthusiastically as this was unique activity apart from regular classroom learning. In the workshop, they taught the women how to make reflective solar cookers. During the workshop, students and women were divided into groups with kids of the village also joining in. The groups were made in such a fashion that every group has at least two to three students along with village women. The students made solar cookers in front of the women and then gave the women the chance to make the cookers by themselves. Majority of the women as well as young 

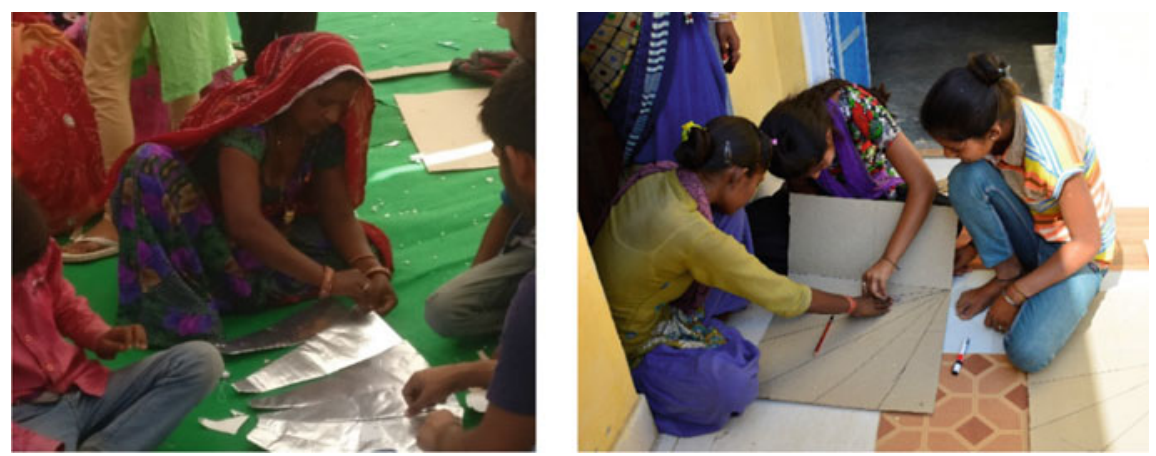

Fig. 24.4 Workshop of village women

kids learned to make these reflective solar cookers by themselves. A demonstration of one of the pre-fabricated solar cookers was given by heating water and later making Khichdi with that cooker. The participants appreciated the technology and realized its benefits over traditional wood burning as it will help them to have healthier cooking environment. This will improve their health as they avoid fumes etc. coming out of burning wood. Few volunteers from Nirmaan also helped in conducting the workshop smoothly. After completion of the workshop all the women were given solar cookers that they had made by themselves for future use. This entire activity was one of the evaluative component of the course. Apart from the evaluation component the students realized their social responsibilities and also learned about the traditional conditions in which village women cook the food. Students also expressed their willingness to participate in future workshops. Figure 24.4. Gives some glimpses of the workshop conducted for the village women with students' involvement.

\subsection{Feedback Survey}

In order to assess the impact of all these activities related to the course, an online feedback survey was conducted. For this, a google form consisting of eight statements was designed and the link was shared with the students through email. The students were asked to give their feedback on 5 point Likert scale with 1 being "strongly disagree", 2 being "disagree", 3 being "Neither agree nor disagree", 4 being "agree" and 5 being "strongly agree". The feedback was collected and the result of the feedback survey given by the students is as shown in Fig. 24.5a-h in the form of bar chart. The feedback survey indicates that majority of students consider this way of learning as very effective, it helped them to work independently, getting involved in multidisciplinary and social activity. This method has also helped them in engaging actively in the class room as it is effective and useful tool to learn complex scientific knowledge easily as compared to the traditional ways. Also due to it their interest towards the course has increased which helped in improvement in their learning. 


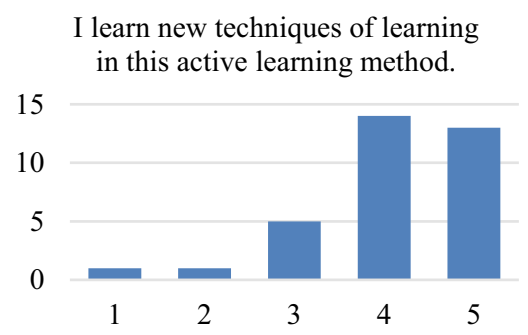

(a)

Through this approach, we are able to do socially useful service.

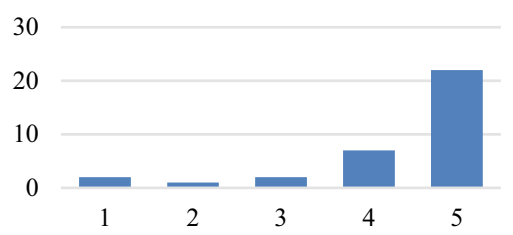

(c)

This method helps me to engage actively in the classroom.

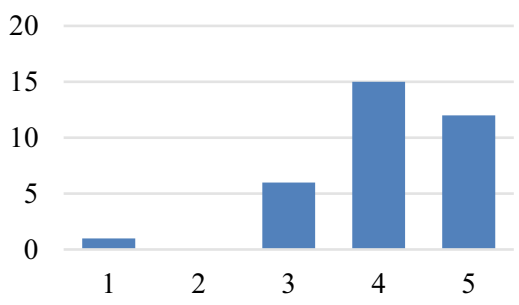

(e)

This method creates interest toward the course which increases selflearning.

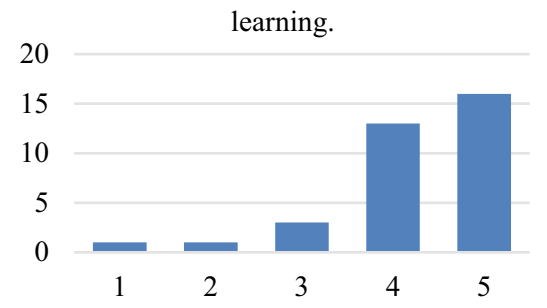

(g)
Through this experiential learning, I am able to conceive and carry out independent work.

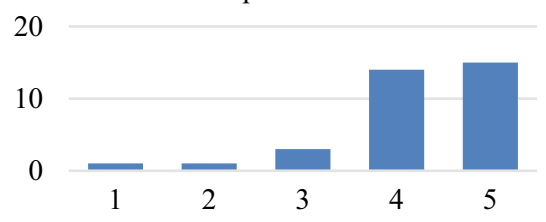

(b)

After going through this experience,

I am able to engage in multidisciplinary work.

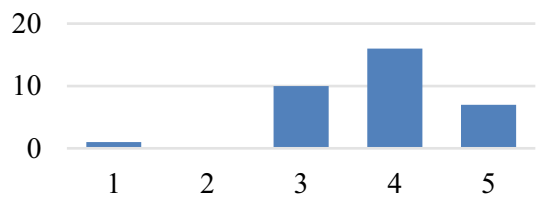

(d)

This active learning method is more efficient for me to learn complex scientific knowledge compare to traditional lecture method.

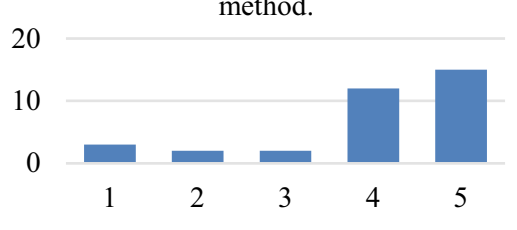

(f)

This method is a useful and effective tool for teaching.

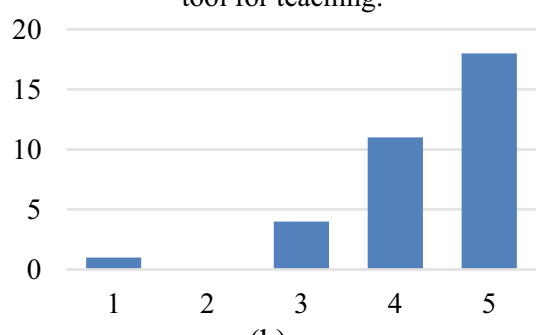

(h)

Fig. 24.5 The feedback survey 


\subsection{Conclusions}

There is immense need to bring innovation in teaching methods for the present generation. Also, among the students, there is need of growing social awareness specially towards weaker section of society as enhancement of the society is very important part in the economy. For effective learning, experiential and collaborative learning has been incorporated in solar energy related courses by the authors at BITS Pilani. Students fabricated do-it-yourself type solar cookers, tested the performance of these cookers in normal conditions and cooked food items using those cookers. With the help of a NGO, students helped the authors to conduct cheap solar cooker workshop for village women at a village near the institute. During the workshop, the students helped the village women to fabricate cheap solar cookers. All the activities fabrication, testing and involvement in the workshop was the part of evaluative components for the courses. It was overall a very successful experiential and collaborative learning experiment along with societal awareness and participation.

\section{References}

Bloom BS (Ed) (1956) Taxonomy of educational objectives. Handbook 1: cognitive domain. WhitePlains, NY, Longman. https://www.uky.edu/ rsand1/china2018/texts/Bloom\% 20et\%20al\%20-Taxonomy\%20of\%20Educational\%20Objectives.pdf. Last accessed 3 July 2019

Davis B, Summers M (2015) Applying Dale's cone of experience to increase learning and retention: a study of student learning in a foundational leadership course. QSci Proc 2015:6. https://doi.org/ 10.5339/qproc.2015.wcee2014.6

Dewey J (2009) Democracy and education: an introduction to the philosophy of education. https:// s3.amazonaws.com/arena-attachments/190319/2a5836b93124f200790476e08ecc4232.pdf. Last accessed 3 July 2019

Heidi MA, Dale's cone of experience. http://www.queensu.ca/teachingandlearning/modules/active/ documents/Dales_Cone_of_Experience_summary.pdf. Last accessed 3 July 2019

Reese HW (2011) The learning-by-doing principle. Behav Develop Bull 17(1):1-19. https://doi. org/10.1037/h0100597

Theodore P (1999) Collaborative versus cooperative learning: a comparison of the two concepts which will help us understand the underlying nature of interactive learning. ERIC Institute of Education Science, pp 1-13. https://files.eric.ed.gov/fulltext/ED448443.pdf. Last accessed 3 July 2019

Vygotsky L (1980) Mind in society: the development of higher psychological processes. Harvard University Press, Cambridge, MA. http://ouleft.org/wp-content/uploads/Vygotsky-Mind-in-Soc iety.pdf. Last accessed 3 July 2019 
Open Access This chapter is licensed under the terms of the Creative Commons Attribution 4.0 International License (http://creativecommons.org/licenses/by/4.0/), which permits use, sharing, adaptation, distribution and reproduction in any medium or format, as long as you give appropriate credit to the original author(s) and the source, provide a link to the Creative Commons license and indicate if changes were made.

The images or other third party material in this chapter are included in the chapter's Creative Commons license, unless indicated otherwise in a credit line to the material. If material is not included in the chapter's Creative Commons license and your intended use is not permitted by statutory regulation or exceeds the permitted use, you will need to obtain permission directly from the copyright holder.

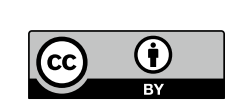

